\title{
Actividad antibacteriana de extractos vegetales frente a cepas intrahospitalarias, Iquitos-Perú
}

\section{Antibacterial activity of plant extracts against nosocomial strains, lquitos-Peru}

\begin{abstract}
Ricardo E. Abadie, Ronald Medina O., Lastenia Ruiz, Alvaro Tresierra-Ayala
Laboratorio de Microbiología. Centro de Investigación de Recursos Naturales de la Universidad Nacional de la Amazonía Peruana (CIRNA-UNAP). Psje. Los Paujiles S/N, San Lorenzo, distrito de San Juan Bautista, lquitos-Perú
\end{abstract}

DOI: https://doi.org/10.33017/RevECIPeru2014.0005/

\section{Resumen}

La región amazónica es una de las áreas que posee la mayor biodiversidad del mundo, albergando varios miles de especies de plantas, muchas de las cuales son utilizadas por sus pobladores como plantas medicinales. Durante los últimos años, el empleo de estos recursos vegetales o de sus productos viene incrementándose de manera importante, lo cual podría deberse a una serie de factores, entre los que destacan el conocimiento de su composición química, y al hecho que en la actualidad se han realizado numerosos ensayos farmacológicos tanto in vivo como in vitro. La aparición de cepas resistentes a los antibióticos comerciales en los últimos tiempos, está creando la necesidad de buscar otras estrategias o alternativas para controlarlas, tal es el caso del uso de las plantas (medicina tradicional), debido a los principios activos que poseen. Se pretende con este trabajo, determinar probables alternativas para combatir infecciones bacterianas de aquellos agentes drogoresistentes, este problema reviste importancia crítica particular en los países en desarrollo, donde quizás no se dispone de antibióticos de segunda línea más costosos o, si los hay, su precio es inasequible. El estudio se realizó en la ciudad de lquitos, Provincia de Maynas, Departamento de Loreto. Los ensayos microbiológicos se realizaron en el Laboratorio de Microbiología del Centro de Investigación de Recursos Naturales de la Amazonia (CIRNA) de la Universidad Nacional de la Amazonia Peruana (UNAP). Se determinó la actividad antibacteriana de 6 extractos vegetales (Alchornea triplinervia, Annona muricata, Averrhoa carambola, Brunfelsia grandiflora, Caraipa grandifolia y Cedrela odorata) mediante la técnica de difusión en disco, y a aquellos que presentaron actividad se les determinó la Concentración Inhibitoria Mínima y la Concentración Bactericida Mínima mediante la técnica de macrodilución en caldo. Ninguno de los extractos tuvieron actividad frente a las cepas de E. coli; cuatro extractos tuvieron actividad frente a las cepas de $P$. aeruginosa, siendo los extractos de Cedrela odorata y Alchornea triplinervia los que tuvieron mayor actividad frente a esta bacteria, con CIM = 15.62 y $62.5 \mathrm{mg} / \mathrm{ml}$, respectivamente; todos los extractos tuvieron actividad frente a las cepas de $S$. aureus, siendo los extracto de C. odorata, A. triplinervia y Caraipa grandiflora, los de mayor actividad con una $\mathrm{CIM}=3.91 \mathrm{mg} / \mathrm{ml}$ para cada uno. Se obtuvieron prometedores resultados de actividad antibacteriana de los extractos en estudio frente a cepas intrahospitalarias, mayormente contra $S$. aureus.

Descriptores: Actividad antibacteriana, extractos vegetales, cepas intrahospitalarias 


\section{Abstract}

The Amazon region is one of the areas with the largest biodiversity in the world, hosting several thousand species of plants, many of which are used by its people as medicinal plants. In recent years, the use of these plant resources or products has been increasing significantly, which could be due to a number of factors, among them the knowledge of their chemical composition, and the fact that at present there have been numerous pharmacological tests both in vivo and in vitro. The emergence of antibiotic-resistant strains in recent years, is creating a need for other strategies or ways to control them, as in the case of the use of plants (traditional medicine), because the active ingredients bearing. This work is intended to determine probable alternatives to combat bacterial infections of those agents antibiotic-resistant, this problem is particularly critical in developing countries, where perhaps there are no antibiotics or expensive second line, if any, price is unavailable. The study was conducted in lquitos city, Province of Maynas, Department of Loreto. Microbiological tests were performed at Microbiology Laboratory of Research Center of Natural Resources of the Amazon (CIRNA) of the National University of the Peruvian Amazon (UNAP). The antibacterial activity of six plant extracts (Alchornea triplinervia, Annona muricata, Averrhoa carambola, Brunfelsia grandiflora, Caraipa grandifolia y Cedrela odorata) by the disk diffusion method was determined, and those that showed activity were determined Minimum Inhibitory Concentration and Minimum Bactericidal Concentration by macrodilution technique. None of the extracts were active against strains of $E$. coli; four extracts had activity against strains of $P$. aeruginosa, with Cedrela odorata and Alchornea triplinervia extracts which had greater activity against these bacteria, with $\mathrm{MIC}=15.62$ and $62.5 \mathrm{mg} / \mathrm{ml}$, respectively; all extracts were active against strains of $S$. aureus, with the extract of $C$. odorata, A. triplinervia and Caraipa grandiflora, the most active with an $\mathrm{MIC}=3.91 \mathrm{mg} / \mathrm{ml}$ for each. Was obtained Promising results of antibacterial activity of the extracts in study against nosocomial strains, mostly against $\mathrm{S}$. aureus.

\section{Keywords: Antibacterial activity, plant extracts, nosocomial strains}

\section{Introducción}

La región amazónica es una de las áreas que posee la mayor biodiversidad del mundo, albergando varios miles de especies de plantas, muchas de las cuales son utilizadas por sus pobladores como plantas medicinales [1]. Durante los últimos años, el empleo de estos recursos vegetales o de sus productos viene incrementándose de manera importante, lo cual podría deberse a una serie de factores, entre los que destacan el conocimiento de su composición química, y al hecho que en la actualidad se han realizado numerosos ensayos farmacológicos tanto in vivo como in vitro [2].

Algunos pacientes que reciben terapia a base de antibióticos muchas veces dicho tratamiento resulta ineficaz, puesto que el intercambio de elementos genéticos de resistencia, ha propiciado el surgimiento de cepas bacterianas drogorresistentes; las cuales son difíciles de controlar empleando antibióticos, haciéndose a menudo persistentes en muchos ambientes, como es el caso de ciertas cepas bacterianas que se vuelven endémicas en ambientes intrahospitalarios, constituyéndose en una amenaza o problema para la salud pública. De modo que, muchas de las bacterias aisladas de ambientes intrahospitalarios pueden mostrar drogorresistencia frente a los antibióticos de uso frecuente. Hoy en día, muchas cepas bacterianas son resistentes a la mayor parte o la totalidad de los antibióticos que alguna vez fueron eficaces para combatirlas [3]. Por todo lo expuesto, en el presente estudio se planteó los objetivos de determinar la actividad antibacteriana de extractos vegetales sobre cepas intrahospitalarias así mismo, determinar la Concentración Inhibitoria Mínima de estos.

\section{Materiales y Métodos}

La primera etapa estuvo orientada a determinar si los extractos presentaban 0 no actividad antibacteriana frente a las cepas aisladas de los hardwares de las computadoras del Hospital César Garayar-lquitos, para tal fin se empleó el método de difusión en agar, empleando discos de papel de filtro y como medio de cultivo agar Müller Hinton (MH). Aquellos extractos que presentaron actividad antibacteriana se les determinó la Concentración Inhibitoria Mínima (CIM) y la Concentración Bactericida Mínima (CBM), esto se realizó por el método de macrodilución en caldo.

\subsection{Obtención de los extractos vegetales}

Fueron proporcionados por el Laboratorio de Investigación de Productos Naturales Antiparasitarios de la Amazonía (LIPNAA) del Centro de Investigación de Recursos Naturales de la Amazonia (CIRNA) de la UNAP. Se utilizó el extracto 
hidroalcohólico de la corteza de Alchornea triplinervia, de la hoja de Annona muricata, corteza Caraipa grandifolia, y hoja de Brunfelsia grandiflora, extracto metanólico de la hoja de Averrhoa carambola, y extracto etanólico de la corteza de Cedrela odorata.

\subsection{Cepas bacterianas}

Se utilizaron 19 cepas de Staphylococcus aureus, 10 cepas de Pseudomonas aeruginosa y 5 de Escherichia coli, aisladas de los teclados y "ratones" de las computadoras del Hospital Cesar Garayar, lquitos. Todas estas cepas fueron conservadas en caldo tripticasa de soya al $20 \%$ de glicerol a $-70{ }^{\circ} \mathrm{C}$.

\subsection{Determinación de la actividad antibacteriana de los extractos}

Se prepararon soluciones stock de cada extracto a una concentracion de $1 \mathrm{~g} / \mathrm{ml}$ en agua esteril. Posteriormente, utilizando papel filtro Whatman $\mathrm{N}^{\circ} 3$ y un perforador convencional se confeccionaron los discos, que fueron esterilizados en el horno a $180^{\circ} \mathrm{C}$ por 1.5 horas y se les agregó, por separado, $15 \mu \mathrm{L}$ de la solución stock de cada extracto y se les dejó secar durante $24 \mathrm{~h}$ o el tiempo necesario a temperatura ambiente. Los discos impregnados con los extractos fueron conservados a $-20^{\circ} \mathrm{C}$, hasta su utilización.

\subsection{Preparación del inóculo y prueba de sensibilidad}

Las cepas fueron repicadas en agar tripticasa de soya e incubadas a $37^{\circ} \mathrm{C}$ por $24 \mathrm{~h}$ para obtener cultivos jóvenes. Luego, se prepararon suspensiones bacterianas en $5 \mathrm{ml}$ de solución salina fisiológica estéril hasta alcanzar la densidad bacteriana equivalente al estándar 0.5 del Nefelómetro de McFarland (1.5 x $\left.10^{8} \mathrm{UFC} / \mathrm{ml}\right)$. Se sumergió un hisopo estéril en la suspensión y se rotó el hisopo varias veces presionando firmemente sobre la pared interior del tubo por encima del nivel del líquido para remover el exceso de inóculo. Se inoculó en toda la superficie de la placa con agar Müller Hinton, realizando estrías con el hisopo, en tres direcciones, para asegurar una distribución uniforme del inóculo. Se dejó secar la placa a temperatura ambiente durante 3 a 5 minutos para que cualquier exceso de humedad superficial sea absorbido. Con la ayuda de una pinza estéril, se colocaron sobre la superficie del agar, los discos impregnados con los respectivos extractos, presionando suavemente sobre cada disco para asegurar un contacto completo con la superficie del agar. Transcurridos 15 minutos, se incubaron las placas en posición invertida a $37{ }^{\circ} \mathrm{C}$ durante $24 \mathrm{~h}$. Al cabo de ese tiempo, con la ayuda de un vernier, se procedió a medir los diámetros de las zonas de inhibición generadas por cada extracto (incluyendo el diámetro del disco). Se utilizó como control positivo a imipenem para E. coli, a cefepime para $P$. aeruginosa y a tetraciclina para $S$. aureus. El criterio utilizado para determinar la actividad antibacteriana fue la presencia o ausencia de halos de inhibición producida por los extractos frente a los microorganismos, sin considerar el tamaño de los mismos, como indicador de grado de sensibilidad $[4,5]$.

\subsection{Determinación de la Concentración Inhibitoria Mínima (CIM)}

Se prepararon cultivos de $18 \mathrm{~h}$, de las bacterias en estudio, en agar tripticasa de soya. Luego se preparó una suspensión bacteriana en solución salina estéril a una turbidez equivalente al estándar 0.5 de la escala de McFarland (aproximadamente $\left.1.5 \times 10^{8} \mathrm{UFC} / \mathrm{ml}\right)$. A continuación, se hizo una dilución al 1/100 (aproximadamente $1.5 \times 10^{6}$ $\mathrm{UFC} / \mathrm{ml})$ transfiriendo $100 \mu \mathrm{L}(0.1 \mathrm{ml})$ de la suspensión bacteriana a $9.9 \mathrm{ml}$ de caldo tripticasa de soya (TSB). Se tuvo listo 10 tubos con $1 \mathrm{ml}$ de caldo tripticasa de soya para cada prueba (tubo $\mathrm{N}^{\circ} 1$ al tubo $\left.\mathrm{N}^{\circ} 10\right)$. Por otro lado, se preparó una solución madre del extracto vegetal a una concentración de $500 \mathrm{mg} / \mathrm{ml}$. Se añadió $1 \mathrm{ml}$ de la solución madre del extracto vegetal al tubo $\mathrm{N}^{\circ} 1$ que contenía $1 \mathrm{ml}$ de caldo tripticasa de soya (concentración del extracto en este tubo es $250 \mathrm{mg} / \mathrm{ml}$ ), se mezcló bien con la ayuda de un vórtex. A partir de este tubo, se prepararon diluciones dobles seriadas, para lo cual se tomó $1 \mathrm{ml}$ y se transfirió al tubo $\mathrm{N}^{\circ} 2$ (concentración del extracto $=125 \mathrm{mg} / \mathrm{ml}$ ), después de mezclar bien el contenido, se transfirió $1 \mathrm{ml}$ al tercer tubo, del cual la concentración de extracto fue $62.5 \mathrm{mg} / \mathrm{ml}$ y así sucesivamente hasta el tubo $\mathrm{N}^{\circ} 10$, del cual se tomó y descartó $1 \mathrm{ml}$. De este modo, se obtuvieron diluciones dobles de cada extracto desde $250 \mathrm{mg} / \mathrm{ml}$ hasta $0.49 \mathrm{mg} / \mathrm{ml}$.

Se añadió a cada tubo con el extracto vegetal (Tubo $\mathrm{N}^{\circ} 1$ al 10), $1 \mathrm{ml}$ del inóculo preparado de la cepa que contiene aproximadamente $1.5 \times 10^{6} \mathrm{UFC} / \mathrm{ml}$, esto supone un inóculo final aproximado de $7.5 \times$ $10^{5} \mathrm{UFC} / \mathrm{ml}$ y las concentraciones finales de los extractos fueron desde $125 \mathrm{mg} / \mathrm{ml}$ hasta $0.24 \mathrm{mg} / \mathrm{ml}$. Los tubos fueron incubados a $37^{\circ} \mathrm{C}$ durante 18 horas y luego se procedió a calcular la CIM, considerándolo como la concentración 
correspondiente al tubo con menor concentración del extracto donde no hubo desarrollo bacteriano, demostrado por la ausencia de turbidez.

\subsection{Determinación de la Concentración Bactericida Mínima (CBM)}

A partir de cada uno de los tubos sin desarrollo bacteriano, se inoculó $0.1 \mathrm{ml}$ en placas con agar tripticasa de soya y con una asa bacteriológica se estrió en toda la superficie del agar en tres direcciones, las que se incubó a $37{ }^{\circ} \mathrm{C}$ durante 18 horas. Finalmente, para determinar la CBM se contó el número de colonias en las placas, considerándose dicha CBM como la menor concentración del extracto cuyo subcultivo produjo un número de colonias menor al $0.1 \%$ del inóculo original $(7.5 \mathrm{x}$ $10^{5} \mathrm{UFC} / \mathrm{ml}$ ), es decir, un número menor a 750 UFC/ml, y como se inoculó la décima parte de $1 \mathrm{ml}$ $(0.1 \mathrm{ml})$, entonces se consideró la CBM al subcultivo que produjo menos de 75 colonias.

\section{Resultados}

\subsection{Susceptibilidad de las cepas de Escherichia coli, frente a los extractos}

En las pruebas in vitro de sensibilidad, mediante difusión en disco, todos los extractos vegetales en estudio no presentaron ninguna actividad antibacteriana frente a las cepas de Escherichia coli, dado que no se observó ninguna formación de halo de inhibición alrededor de los discos, permitiendo a la bacteria desarrollarse libremente en toda la superficie del agar.

Tabla 1: Datos descriptivos de los halos de inhibición de los extractos con actividad frente a Pseudomonas aeruginosa.

\subsection{Susceptibilidad de las cepas de Pseudomonas aeruginosa, frente a los extractos}

En las pruebas in vitro de sensibilidad, mediante difusión en disco, 4 de los 6 extractos vegetales en estudio presentaron actividad antibacteriana frente a las 10 cepas de Pseudomanas aeruginosa. Los que presentaron actividad frente a este agente patógeno fueron el extracto hidroalcohólico de la corteza de Alchornea triplinervia, el extracto hidroalcohólico de la hoja de Brunfelsia grandiflora, el extracto hidroalcohólico de la corteza de Caraipa grandifolia y el extracto etanólico de la corteza de Cedrela odorata. Mientras que los extractos que no presentaron ninguna actividad frente a $P$. aeruginosa fueron el extracto hidroalcohólico de la hoja de Annona muricata y el extracto metanólico de la hoja de Averrhoa carambola.

Los extractos que tuvieron mayor actividad frente a las cepas de $P$. aeruginosa en relación al diámetro de los halos de inhibición que presentaron, fueron el extracto hidroalcohólico de la corteza de Alchornea triplinervia (12.55 $\mathrm{mm}$ de promedio de diametro) y el extracto etanólico de la corteza de $C$. odorata (12.45 $\mathrm{mm}$ de promedio). Los extractos que tuvieron menos actividad con respecto a los halos de inhibición que presentaron frente a $P$. aeruginosa fueron el extracto hidroalcohólico de la corteza de C. grandifolia (9.7 $\mathrm{mm}$ de promedio) y el extracto hidroalcohólico de la hoja de $B$. grandiflora ( $8.55 \mathrm{~mm}$ de promedio) (Tabla 1).

\begin{tabular}{|l|c|c|c|c|c|}
\hline \multirow{2}{*}{ Extracto de planta } & \multicolumn{5}{|c|}{$\begin{array}{c}\text { Datos descriptivos de los halos de inhibición de los } \\
\text { extractos contra } P \text {. aeruginosa }(\mathrm{mm})\end{array}$} \\
\cline { 2 - 6 } & Promedio & DS & Mediana & $\begin{array}{c}\text { Valor } \\
\text { Máximo }\end{array}$ & $\begin{array}{c}\text { Valor } \\
\text { Mínimo }\end{array}$ \\
\hline Alchornea triplinervia & 12.55 & 3.55 & 12.25 & 18.5 & 8 \\
\hline Brunfelsia grandiflora & 8.55 & 1.66 & 8 & 12 & 7 \\
\hline Caraipa grandifolia & 9.7 & 1.67 & 10 & 12.5 & 7 \\
\hline Cedrela odorata & 12.45 & 3.07 & 12.75 & 17 & 8 \\
\hline
\end{tabular}

Fuente: Base de datos del proyecto (2014), DS = Desviación estándar 
Tabla 2: Datos descriptivos de los halos de inhibición de los extractos con actividad frente a Staphylococcus aureus.

\begin{tabular}{|l|c|c|c|c|c|}
\hline \multirow{3}{*}{ Extracto de planta } & \multicolumn{6}{|c|}{ Datos descriptivos de los halos de inhibición de los } \\
& extractos contra S. aureus (mm) & \multicolumn{2}{l|}{} \\
\cline { 2 - 6 } & Promedio & DS & Mediana & $\begin{array}{c}\text { Valor } \\
\text { Máximo }\end{array}$ & $\begin{array}{c}\text { Valor } \\
\text { Mínimo }\end{array}$ \\
\hline Alchornea triplinervia & 17.92 & 2.95 & 18 & 23.5 & 13.5 \\
\hline Annona muricata & 11.05 & 2.38 & 11 & 15 & 7 \\
\hline Averrhoa carambola & 10.61 & 1.74 & 10 & 15 & 8 \\
\hline Brunfelsia grandiflora & 10.89 & 2.87 & 11 & 18 & 7.5 \\
\hline Caraipa grandifolia & 13.29 & 2.30 & 13 & 17.5 & 9.5 \\
\hline Cedrela odorata & 16.68 & 3.13 & 16.5 & 24.5 & 13 \\
\hline
\end{tabular}

Fuente: Base de datos del proyecto (2014), DS = Desviación estándar

Tabla 3: Concentración Inhibitoria Mínima (CIM) y Concentración Bactericida Mínima (CBM) de los extractos contra las cepas de $P$. eruginosa y $S$. aureus.

\begin{tabular}{|l|c|c|c|c|}
\hline \multirow{2}{*}{ EXTRACTOS } & \multicolumn{2}{|c|}{ Pseudomonas aeruginosa } & \multicolumn{2}{c|}{ Staphylococcus aureus } \\
\cline { 2 - 5 } & $\begin{array}{c}\mathrm{CIM} \\
(\mathrm{mg} / \mathrm{ml})\end{array}$ & $\begin{array}{c}\text { CBM } \\
(\mathrm{mg} / \mathrm{ml})\end{array}$ & $\begin{array}{c}\mathrm{CIM} \\
(\mathrm{mg} / \mathrm{ml})\end{array}$ & $\begin{array}{c}\mathrm{CBM} \\
(\mathrm{mg} / \mathrm{ml})\end{array}$ \\
\hline Cedrela Odorata & 15.62 & 125 & 3.91 & 7.81 \\
\hline Alchornea triplinervia & 62.5 & 250 & 3.91 & 15.62 \\
\hline Caraipa grandifolia & 250 & 500 & 3.91 & 15.62 \\
\hline Averrhoa carambola & S.A & S.A & 15.62 & 62.5 \\
\hline Annona muricata & S.A & S.A & 31.25 & 125 \\
\hline Brunfelsia grandiflora & 125 & 250 & 125 & 500 \\
\hline
\end{tabular}

Fuente: Base de datos del Proyecto (2014); S.A.: Sin Actividad

3.3 Susceptibilidad de las cepas de Staphylococcus aureus, frente a los extractos

En las pruebas de sensibilidad in vitro, mediante difusión en disco, todos los extractos en estudio tuvieron actividad antibacteriana frente a las 19 cepas de $S$. aureus. Los extractos que tuvieron mayor actividad frente a las cepas de $S$. aureus en relación al diámetro de los halos de inhibición que presentaron, fueron el extracto hidroalcohólico de la corteza de Alchornea triplinervia (17.92 mm de promedio del diámetro) y el extracto etanólico de la corteza de C. odorata (16.68 $\mathrm{mm}$ de promedio). Seguido por el extracto hidroalcohólico de la corteza de Caraipa grandifolia $(13.29 \mathrm{~mm}$ de promedio). Los extractos que tuvieron menos actividad con respecto a los halos de inhibición fueron el extracto hidroalcohólico de la hoja de Annona muricata (11.05 $\mathrm{mm}$ de promedio), el extracto hidroalcohólico de la hoja de Brunfelsia grandiflora (10.89 $\mathrm{mm}$ de promedio) y el extracto metanólico de la hoja de Averrhoa carambola (10.61 $\mathrm{mm}$ de promedio). (Tabla 2)

3.4 Concentración Inhibitoria Mínima (CIM) y Concentración Bactericida Mínima (CBM) de los extractos frente a las cepas de Pseudomonas aeruginosa y Staphylococcus aureus.

El extracto que tuvo la menor Concentración Inhibitoria Mínima (CIM) y la menor Concentración 
Bactericida Mínima (CBM) en las cepas de $P$. aeruginosa fue el extracto etanólico de la corteza de Cedrela odorata con una CIM = $15.62 \mathrm{mg} / \mathrm{ml}$ y una $\mathrm{CBM}=125 \mathrm{mg} / \mathrm{ml}$, seguido por el extracto hidroalcohólico de la corteza de Alchornea triplinervia con una $\mathrm{CIM}=62.5 \mathrm{mg} / \mathrm{ml}$ y una $\mathrm{CBM}=$ $250 \mathrm{mg} / \mathrm{ml}$. El extracto hidroalcohólico de la hoja de Brunfelsia grandiflora tuvo una CIM $=125$ $\mathrm{mg} / \mathrm{ml}$ y una $\mathrm{CBM}=250 \mathrm{mg} / \mathrm{ml}$, y el extracto hidroalcohólico de la corteza de Caraipa grandifolia tuvo una $\mathrm{CIM}=250 \mathrm{mg} / \mathrm{ml}$ y una $\mathrm{CBM}=500$ $\mathrm{mg} / \mathrm{ml}$. (Tabla 3).

Los extractos que tuvieron una menor Concentración Inhibitoria Mínima (CIM) y menor Concentración Bactericida Mínima (CBM) en las cepas de $\mathrm{S}$. aureus fueron el extracto etanólico de la corteza de Cedrela odorata, el extracto hidroalcohólico de la corteza de Alchornea triplinervia y el extracto hidroalcohólico de la corteza de Caraipa grandifolia con una CIM para cada uno $=3.91 \mathrm{mg} / \mathrm{ml}$ y una $C B M=7.81 \mathrm{mg} / \mathrm{ml}$, $15.62 \mathrm{mg} / \mathrm{ml}$ y $15.62 \mathrm{mg} / \mathrm{ml}$, respectivamente. El extracto metanólico de la hoja de Averrhoa carambola tuvo una CIM $=15.62 \mathrm{mg} / \mathrm{ml}$ y una $\mathrm{CBM}=62.5 \mathrm{mg} / \mathrm{ml}$, el extracto hidroalcohólico de la hoja de Annona muricata tuvo una $\mathrm{CIM}=31.25$ $\mathrm{mg} / \mathrm{ml}$ y una $\mathrm{CBM}=125 \mathrm{mg} / \mathrm{ml}$ y el extracto hidroalcohólico de la hoja de Brunfelsia grandiflora tuvo una $\mathrm{CIM}=125 \mathrm{mg} / \mathrm{ml}$ y una $\mathrm{CBM}=500$ $\mathrm{mg} / \mathrm{ml}$. (Tabla 3).

\section{Discusión}

El extracto hidroalcohólico de la corteza de Alchornea triplinervia fue una de las que tuvo mayor actividad frente a las cepas de $S$. aureus y $P$. aeruginosa conjuntamente con Cedrela odorata; sin embargo, existen escasas publicaciones respecto a esta planta, mucho menos de sus propiedades antimicrobianas, como el de Calvo et al. [6] donde en su estudio de actividad antibacteriana del extracto metanólico de las hojas de esta planta mostraron una actividad prometedora contra $S$. aureus, corroborando a nuestro estudio de que esta planta tiene un gran potencial antimicrobiano para estudios posteriores.

El extracto hidroalcohólico de la hoja de Annona muricata, presentó actividad antibacteriana frente a las 19 cepas de Staphylococcus aureus, en otros estudios similares realizado por Viera et al. [7] y Pathak et al. [8] también encontraron actividad antibacteriana de esta planta, utilizando el extracto acuoso de su cáscara y el extracto metanólico de su hoja, respectivamente, el cual presentó actividad frente a la cepa de $S$. aureus ATCC25923 y ATCC29213, respectivamente, por otra parte Álvarez et al (1999) también han encontrado actividad antibacteriana frente a $S$. aureus utilizando el extracto acuoso de su hoja. Viera et al. [7] trabajaron además con cepas de Escherichia coli, donde el extracto (acuoso y etanólico) de la cascara de $A$. muricata no presentaron actividad antibacteriana, lo que concuerda con los resultados registrados en este estudio, de que esta planta no presenta actividad antibacteriana frente a $E$. coli, considerando tanto la parte de la planta y el tipo de extracto que ellos usaron; pero sin embargo, Álvarez et al. [9] y Pathak et al. [8] encontraron que el extracto de la hoja de $A$. muricata presenta actividad antibiótica frente a esta bacteria, en contraste con lo reportado por Viera et al. [7] y por lo reportado en este estudio, esto puede deberse a muchos factores, como a la cepa bacteriana, el tipo de extracto y/o parte de la planta del que se obtiene, la concentraciones utilizadas, metodología, geografía entre otros.

El extracto metanólico de Averrhoa carambola empleado en el presente trabajo de tesis, mostró actividad antibacteriana frente a todas las cepas de $S$. aureus (19), y no mostró actividad frente a las cepas de E.coli y $P$. aeruginosa; estudios similares por Wakte \& Patil [10] que el extracto metanólico de la fruta inhibían el crecimiento de $S$. aureus ATCC6538P y $P$. aeruginosa ATCC19429, mas no inhibían el crecimiento de E. coli ATCC25922, estos resultados coincidían parcialmente con lo registrado en el presente estudio, toda vez que fueron similares para el caso de $S$. aureus y E. coli, mas no para $P$. aeruginosa. Cabe mencionar que Wakte y Patil [10] registraron mejores resultados con los extractos obtenidos por el método de extracción fría, que pude ser debido a la presencia de principios bioactivos termolábiles altamente potentes que se encontró a disminuir la calentura del solvente; el método que utilizaron aquellos autores para determinar la actividad antibacteriana fue por difusión en agar en pocillos conteniendo el extracto crudo, diferente a lo realizado en la presente tesis que fue por difusión en discos impregnados con los extractos, lo cual posiblemente explique la diferencia de actividad inhibitoria entre nuestros extractos y lo reportado en la literatura.

En cuanto al extracto hidroalcohólico de la hoja de $B$. grandiflora mostró actividad contra las cepas de $S$. aureus y $P$. aeruginosa, mas no manifestó actividad alguna contra las cepas de E. coli, 
resultados similares mostraron Kloucek et al. [11] quienes trabajaron con diferentes extractos de plantas provenientes de Pucallpa, concluyendo que el extracto etanólico de la raíz de $B$. grandiflora presenta actividad frente a $S$. aureus ATCC25923 y $P$. aeruginosa ATCC27853, mas no para E. coli ATCC25922, lo cual coinciden con los resultados a este estudio pese a haber empleado diferentes solvente y estructura vegetal.

Existen muy pocos antecedentes con respecto a la actividad antibacteriana de Caraipa grandifolia, en el presente estudio el extracto hidroalcohólico de la corteza de esta planta fue uno de las que mostró mayor actividad frente a $S$. aureus, una bacteria Grampositiva, mientras que por otro lado fue el extracto que tuvo la menor actividad frente a $P$. aeruginosa y ninguna actividad frente a $E$. coli, ambas bacterias Gramnegativas; Suffredini et al. [12] tuvo resultados similiares, donde menciona que el extracto orgánico de las hojas de $C$. grandifolia mostró actividad frente $S$. aureus, pero no mostraron actividad frente a $P$. aeruginosa y $E$. coli; pudiendo deducir por lo reportado en ambos estudios que esta planta tiene mejor actividad frente a bacterias Grampositivas.

Existen escasos reportes científicos respecto a las propiedades antimicrobianas Cedrela odorata. Cáceres et al [13] reportaron que el extracto etanólico de las hojas no inhibe el desarrollo de Escherichia coli, respecto a las propiedades antibacterianas de la corteza, la OPS/OMS [14] han reportado que los extractos etanólicos de hojas y de la corteza inhiben el desarrollo de $S$. aureus en cultivo, mientras que el extracto etanólico de la raíz inhibe el desarrollo de $E$. coli. Por otro lado Flores ([15], observó que los extractos de la corteza obtenidos con metanol, agua y metanol-agua inhibieron el crecimiento de $S$. aureus, E. coli, cuando se emplearon en concentraciones de 25 a $200 \mathrm{mg} / \mathrm{ml}$. Es importante mencionar que Flores [15], obtuvo sus extractos mediante calentamiento a reflujo por tres horas, mientras que este trabajo de tesis y en los demás antes mencionados, fueron obtenidos por maceración, lo que posiblemente explique la diferencia de actividad inhibitoria. En el presente estudio, el extracto etanólico de la corteza de Cedrela odorata presentó buena actividad antibacteriana frente a las cepas de $S$. aureus y $P$. aeruginosa, y no presentó ninguna actividad frente a las cepas de E. coli. Otros estudios realizados por Rojas \& Rodriguez [16] reportaron que el extracto etanólico de la corteza de $C$. odorata presenta una $\mathrm{CIM}=12.5 \mathrm{mg} / \mathrm{ml}$ frente a $S$. aureus
ATCC6538, valor que está muy por encima que el registrado en el presente estudio $(\mathrm{CIM}=3.91$ $\mathrm{mg} / \mathrm{m})$.

De acuerdo a la literatura consultada, no se ha encontrado ningún estudio en el cual se haya ensayado cepas bacterianas intrahospitalarias, lo cual constituye un hecho muy transcendente, más aun si se toma en consideración que muchas de estas cepas pueden presentar un perfil de resistencia antibiótica hiperresistente, por lo que el empleo de extractos vegetales podría ser una gran alternativa para su control y eliminación.

\section{Conclusiones}

Ninguno de los extractos vegetales ensayados fue activo contra Escherichia coli.

El extracto de Cedrela odorata fue el más activo tanto contra Pseudomonas aeruginosa y Staphylococcus aureus.

Las Concentraciones Inhibitorias y Bactericidas Mínimas de los extractos con actividad, fueron mucho menores para Staphylococcus aureus que para Pseudomonas aeruginosa.

Los extractos de Cedrela odorata y de Alchornea triplinervia poseen una prometedora actividad contra las bacterias de origen intrahospitalario

\section{Agradecimientos}

Nos gustaría reconocer y alcanzar nuestra más sincera gratitud al Dr. Álvaro Tresierra, y a la Dra. Lastenia Ruiz por sus guías y por su enorme apoyo para la realización de este estudio. Nos mostraron diferentes formas de abordar un problema y la necesidad de ser persistente para lograr cualquier meta.

\section{Referencias}

[1] Mori, T; Ruiz, E; Bardales, J; Garcia, M; Tresierra, A; Arevalo, L; Bendayan, M; Dávila, C; Espinosa, F; Reátegui, R; Angulo, J; Quevedo, C \& Zapata, E. 2010. Efecto Antimicrobiano de Myrciaria dubia "Camu Camu" y Cyperus luzulae "Piripiri" sobre Microorganismos Patógenos.

[2] Araujo, J \& Salas, R. 2008. Actividad Antimicrobiana de Plantas. Revista Científica. Universidad Científica del Sur. Lima, Perú. 
[3] OMS. 2002. Prevención de las Infecciones Nosocomiales. Guía Práctica. 2 ${ }^{\mathrm{a}}$ Edicion. Ginebra, Suiza. 71pp.

[4] Toribio, M. S.; Oriani, S.D.; Toso, R.E; Tortone, C.A, Fernandez, J.G. 2007. Suceptibilidad de Staphylococcus aureus a extractos vegetales obtenidos de plantas nativas y naturalizadas de la provincia de la Pampa, Argentina.

[5] Toribio, M. S.; Oriani, S.D.;Toso, R.E; Tortone, C.A, Fernandez, J.G. 2009. Staphylococcus aureus sensible a extractos metanolicos obtenidos de plantas nativas de la provincia de la Pampa, Argentina.

[6] Calvo, t; Demarco, D; Santos, V; Moraes, $\mathrm{H}$; Bauab, T; Varanda, E; Colus, i \& Vilegas, W. 2004. Sustainable use of biodiversity in Brazil -chemical pharmaceutical prospecting in higher plants: Alchornea glandulosa, triplinervia Alchornea (Euphorbiaceae), andtruxillensis Indigofera, suffruticosa Indigofera (Fabaceae).

[7] Vieira, G; Mourão, J; Ângelo, A; Costa, R \& Viera R. 2010. Antibacterial effect (in vitro) of Moringa oleifera and Annona muricata against Gram positive and Gram negative bacteria.

[8] Pathak, P; Saraswhaty, D; Vora, A \& Savai, J. 2010.In Vitro Antimicrobial Activity and Phytochemical Analysis of the Leaves of Annona muricata.

[9] Alvarez, C; Simó, L; Ortiz, M \& Mañón D. 1999. Actividad Antibiótica de Seis Plantas Medicinales Dominicanas.
[10] Wakte, S \& Patil, D. 2011.Antimicrobial and Antioxidant Activity of Averrhoa carambola L. Fruit at Various Stages of Ripening.

[11] Kloucek, P., Polesny, Z., Svobodova,B., Vlkova,E., Kokoska, L. 2005. "Antibacterial screening of some Peruvian medicinal plants used in Calleria District."

[12] Suffredinl, I; Paciencia, M; Nepomuceno, D; Younes, R \& Varella, A. 2006. Antibacterial and cytotoxic activity of Brazilian plant extracts - Clusiaceae. Mem Inst Oswaldo Cruz, Vol. 101(3): 287-290.

[13] Cáceres, A., Cano P, O., Samayoa, B. Aguilar, L. 1990. Plants used in Guatemala for the treatment of gastrointestinal disorders. 1. Screening of 84 plants against enterobacteria. J. Ethnopharmacol, 30:5573.

[14] OPS/OMS.1995. Plantas de uso medicinal en Centro América. Cooperación Italiana. Guatemala.

[15] Flores, G. 2001. Determinación del Efecto de Cedrela Odorata L. sobre la proliferación in vitro de Bacterias, Células Hematopoyéticas Normales y Células Humanas Transformadas. Universidad Autónoma Metropilitana. Mexico. 26pp.

[16] ROJAS, N \& RODRÍGUEZ, M. 2008. Actividad Antimicrobiana de Tectona grandis L. f., Bursera simaruba (L.) Sarg. Y Cedrela odorata L. Rev Cubana Plant Med. 